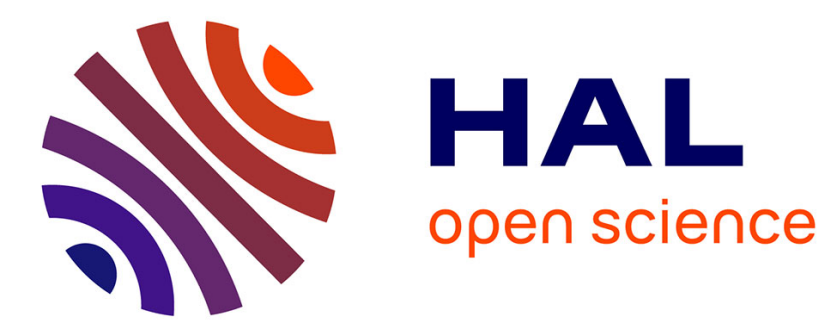

\title{
Synchrotron radiation induced photoionization and photodissociation of small molecules
}

P. Erman, A. Karawajczyk, E. Rachlew-Källne, S. Sorensen, C. Strömholm

\section{To cite this version:}

P. Erman, A. Karawajczyk, E. Rachlew-Källne, S. Sorensen, C. Strömholm. Synchrotron radiation induced photoionization and photodissociation of small molecules. Journal de Physique IV Proceedings, 1994, 04 (C9), pp.C9-393-C9-396. 10.1051/jp4:1994965 . jpa-00253528

\section{HAL Id: jpa-00253528 https://hal.science/jpa-00253528}

Submitted on 1 Jan 1994

HAL is a multi-disciplinary open access archive for the deposit and dissemination of scientific research documents, whether they are published or not. The documents may come from teaching and research institutions in France or abroad, or from public or private research centers.
L'archive ouverte pluridisciplinaire HAL, est destinée au dépôt et à la diffusion de documents scientifiques de niveau recherche, publiés ou non, émanant des établissements d'enseignement et de recherche français ou étrangers, des laboratoires publics ou privés. 


\title{
Synchrotron radiation induced photoionization and photodissociation of small molecules
}

\author{
P. Erman, A. Karawajczyk, E. Rachlew-Källne, S.L. Sorensen and C. Strömholm \\ Department of Physics I, Royal Institute of Technology, 10044 Stockholm, Sweden
}

Tunable synchrotron radiation makes possible detailed studies of molecular photoionization and photodissociation. This is particular true if the induced reactions may be studied in various decay channels such as formed ions and positive and negative fragments as well as fluorescence in different wavelength regions. We have performed studies of this kind in the low energy range (14-35 eV) using the Swedish synchrotron facility MAX in Lund. A special detection channel has been constructed for the purpose involving two sections, one low pressure chamber with a quadrupole mass spectrometer and one high pressure chamber for fluorescence detection using a variety of photomultipliers. The studies performed so far involve small fundamental molecules such as $\mathrm{N}_{2}[1,2], \quad \mathrm{O}_{2}[3,4], \quad \mathrm{CO}[5]$ and $\mathrm{NO}[6]$ as well as $\mathrm{CO}_{2}[7]$, methane[8] and neopentane[9]. While a great number of the observed lines are already known, several strong lines and series have been classified for the first time. The combination of information from the mass spectra and the fluorescence spectra contribute important information concerning autoionization and predissociation of the involved Rydberg states.

\section{DETECTION OF MASS SPECTRA AND FLUORESCENCE}

The general experimental situation is sketched in Fig. 1 in the case of the single ionization region in the vicinity of the first ionization potential (I.P.). At a given energy $(\mathrm{h} \nu)_{\operatorname{exc}}(\geq \mathrm{I}$.P.) of the exciting synchrotron light a molecule, $\mathrm{AB}$, will dissociate or will be ionized either via a direct process or via a "doorway" Rydberg state (AB)*. In practice the latter process will frequently be far more important and will give rise to a rich line structure in the measured mass spectra $(\mathrm{AB})^{+}, \mathrm{A}^{+}$or fluorescence spectra according to the scheme shown in Fig.1. More specifically $(A B)^{+}$ions are formed in autoionization of $(A B)^{*}$, while $A^{+}$fragments are formed in predissociation either into $\mathrm{A}^{+}+\mathrm{B}^{*}$ or ion pairs $A^{+}+B^{-}$. Fluorescence photons may be emitted from the molecule $(A B)^{+}$ (IR, visible, UV) as well as from excited fragments (generally UV radiation). The combined information from all these decay channels gives a detailed information about photoionization and photodissociation of molecules as well as about the level structure in the single ionization region. 
Fig. 1 Basic processes in photoionization and photodissociation. Ionization and dissociation may either take place through a direct process or via a autoionization or predissociation via "doorway" Rydberg state $(A B)^{*}$. The direct and indirect processes may be studied using various detection channels such as the formed ions $(A B)^{+*}$, $A^{ \pm}, B^{ \pm}$or fluorescence from the molecules $(A B)^{+*}$ or the atoms $B^{*}$ and $A^{*}$. Interferences between the direct and indirect processes give rise to Fano profiles and the doorway states appear as a discrete structure in all detection channels.

Fig.2 Experimental arrangement for detection of ions, ion fragments and fluorescence from synchrotron radiation induced photoionization and photodissociation of free molecules (from ref.[4]).
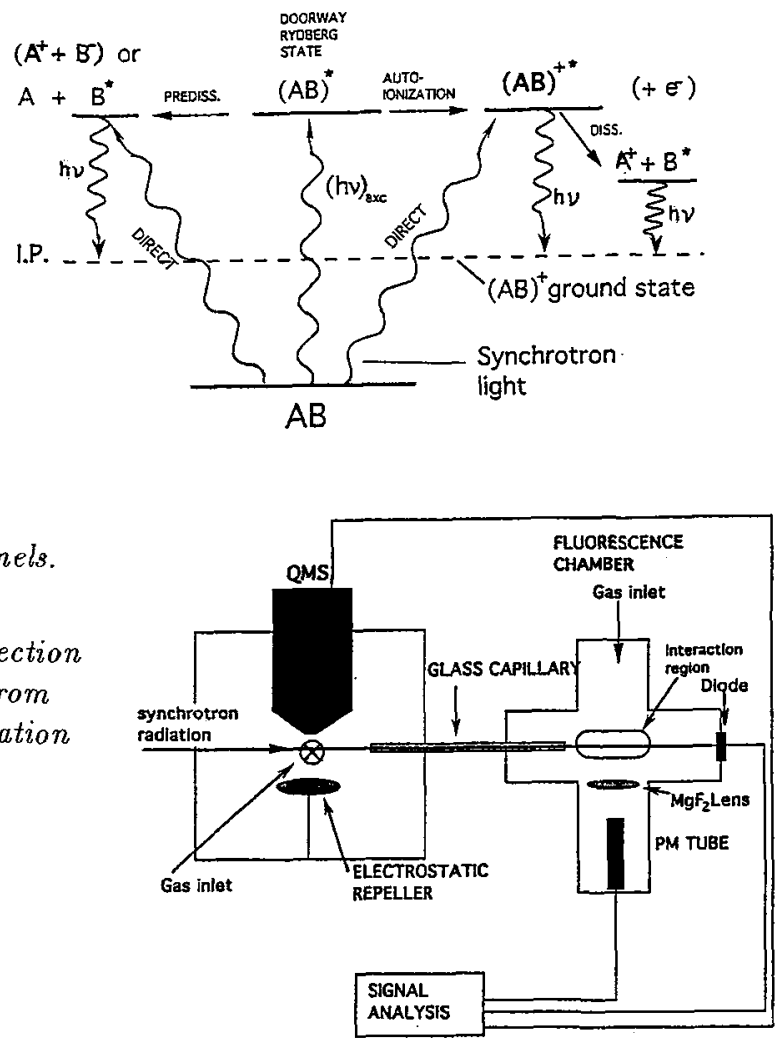

\section{EXPERIMENTAL}

Fig.2 shows our equipment for studies of this kind at the Swedish synchrotron facility MAX in Lund. Dispersed light ( $10-40 \mathrm{eV}$ ) from a $1 \mathrm{~m}$ normal incidence monochromator enters a mass analysis chamber (ambient pressure $\leq 0.01 \mathrm{mTorr}$ ) where the ions and ion fragments are formed from an effusive jet and pushed towards a quadrupole mass spectrometer (QMS) by an electrostatic repeller. A second "high pressure" chamber is attached to the QMS chamber via a capillary, where the fluorescence from a second jet is focussed and detected with various PM tubes for different wavelengths. The total synchrotron flux was continuously monitored using a calibrated silicon diode.

\section{EXAMPLES OF MOLECULES STUDIED AT MAX}

\subsection{Oxygen}

Fig.3 shows the $\left(\mathrm{c}^{4} \Sigma_{u}^{-}\right) 3 \mathrm{~s} \sigma_{g} \quad \mathrm{v}^{\prime}=0,1$ Fano "window" resonances in $\mathrm{O}_{2}$ viewed by detection of $\mathrm{O}_{2}^{+}$ions (a), $5300-6500 \AA$ fluorescence (b), $\mathrm{O}^{+}$ions (c), $1150-3200 \AA$ fluorescence (d), $1150-2000 \AA$ fluorescence (e). A lot of information can be gleaned from this set of curves. Thus, (c) and (e) represent dissociation into $\mathrm{O}^{*}+\mathrm{O}^{+}$and $\mathrm{O}^{*}+$ $\mathrm{O}^{(*)}$ fragments, respectively, and these curves are mutually different and also different from the remaining curves. The explanation follows from the shallow potential curve of the $\left(c^{4} \Sigma_{u}^{-}\right) 3 \mathrm{~s} \sigma_{g}$ state which only supports the $\mathrm{v}^{\prime}=0$ and the $\mathrm{v}^{\prime}=1$ levels. No molecular emission from the latter level occurs in view of rapid tunneling through the barrier, while the $\mathrm{v}^{\prime}=0$ level preferably decays by $\mathrm{c} \rightarrow \mathrm{b}$ emission $(1940-2360 \AA)$. Thus, 
the $\mathrm{v}^{\prime}=1$ emission peak in curve (e) stems from excited $\mathrm{O}^{*}$ dissociation fragments $(\lambda$ $=1302-1304 \AA$ multiplet) while the broad peak to the left of the $v^{\prime}=1$ peak follows from direct dissociation to the repulsive part of the c-potential curve.

\subsection{Nitrogen}

Molecular nitrogen has been exposed to synchrotron light in the range $16-40 \mathrm{eV}$ and the $\mathrm{N}^{+}, \mathrm{N}_{2}^{+}$mass spectra have been studied [1] as well as the fluorescence [2]. Line structures are observed which are interpreted in terms of autoionization or dissociation of well known Rydberg states in $\mathrm{N}_{2}$ converging to the $\mathrm{B}, \mathrm{C}$ and $\mathrm{D}$ states in $\mathrm{N}_{2}^{+}$. In addition a new member of the Rydberg series converging to the $\mathrm{D}$ state is found.
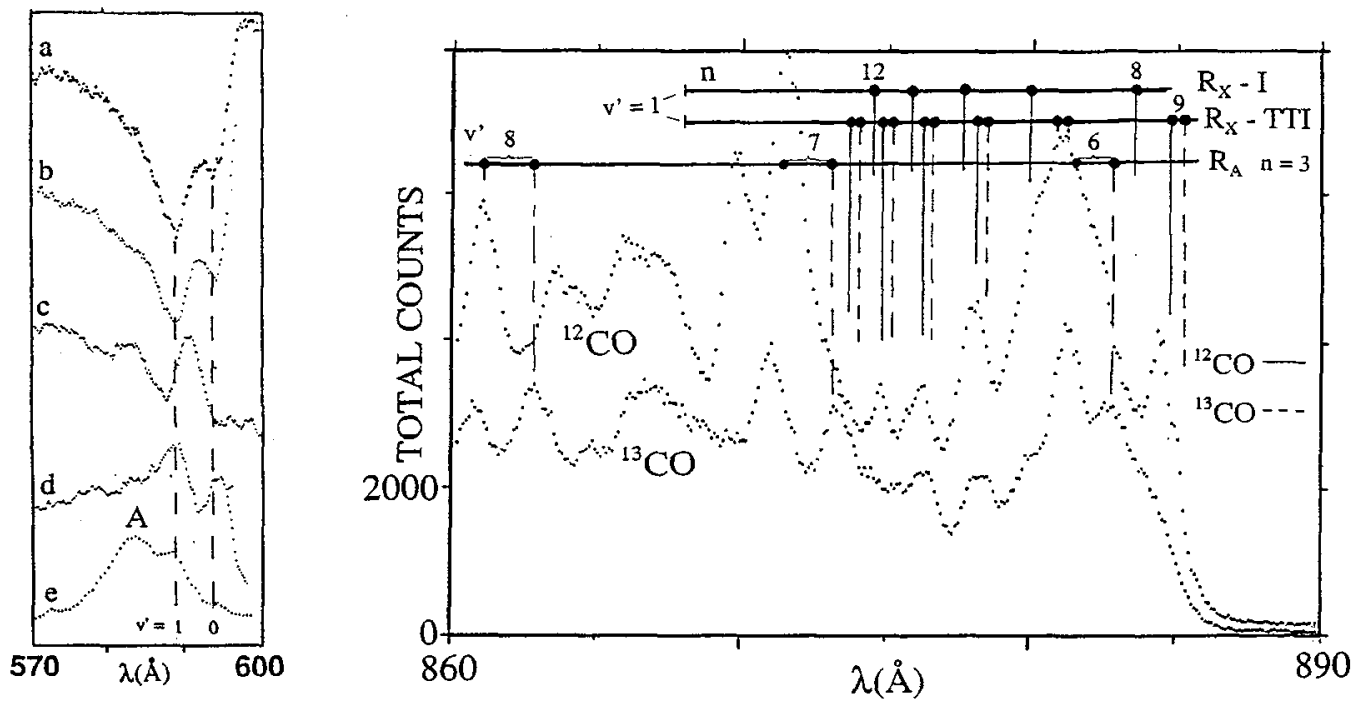

Fig. 3 The Fano resonances $\mathrm{O}_{2}\left(c^{4} \Sigma_{u}^{-}\right) 3 s \sigma_{g}, v^{\prime}=0,1$ viewed in different detection channels. (a): $O_{2}^{+}$ions, $(b):$ fluorescence $5300-6500 \AA,(c): O^{+}$ions, (d): fluorescence $1150-3200 \AA,(e)$ : fluorescence $1150-2000 \AA$. Peak $A$ in curve (e) probably follows from direct bound-free dissociation from the $\mathrm{O}_{2}$ ground state to the left continuum part of the $\left(c^{4} \Sigma_{u}^{-}\right) 3 s \sigma_{g}$ potential curve (from ref[4]).

Fig.4 Production of ${ }^{12} \mathrm{CO}^{+}$and ${ }^{13} \mathrm{CO}^{+}$ions at bombardement of natural $\mathrm{CO}$ gas with $860-890 \AA$ photons. The strongest transitions in the ${ }^{12} \mathrm{CO}^{+}$spectrum have hitherto been unclassified, but the isotope shifts observed above suggest that they form the lowest $(n=3)$ vibrational progression of the $R_{A}$ series (from ref[5]).

\subsection{Carbon monoxide}

The decay products of $\mathrm{CO}$ were studied in various detection channels such as formed $\mathrm{CO}^{+}$and $\mathrm{C}^{+}$ions and visible or VUV fluorescence. A rich line structure is observed which are attributed to $\mathrm{CO}$ Rydberg series converging to the $\mathrm{X}, \mathrm{A}, \mathrm{B}, \mathrm{D}, \mathrm{C}$ and $\mathrm{E}$ states in $\mathrm{CO}^{+}$. While a great number of these lines are already known, some of them are classified here for the first time such as the $\mathrm{R}_{A}(\mathrm{n}=3)$ progression which has been discovered from comparisons of the ${ }^{12} \mathrm{CO}^{+}$and ${ }^{13} \mathrm{CO}^{+}$spectra (Fig.4) 


\subsection{Nitric oxide}

Studies of the photoion excitation (PIE) spectra of $\mathrm{NO}^{+}, \mathrm{N}^{+}, \mathrm{O}^{+}$and $\mathrm{O}^{-}$formed from NO at MAX [6] have yielded extended information about the structure of Rydberg series converging to all known states in $\mathrm{NO}^{+}$below $24 \mathrm{eV}$ and their interactions with other states. Several predissociations have been found caused by a number of $\mathrm{NO}^{+}$ states as well as $\mathrm{NO}$ ion pair states.

\subsection{Polyatomic molecules}

Among the studied species could here be mentioned carbon dioxide[7], methane[8] and neopentane[9]. In the case of $\mathrm{CO}_{2}$ the combined information from the PIE spectra of $\mathrm{CO}_{2}^{+}, \mathrm{CO}^{+}, \mathrm{O}^{+}$and $\mathrm{C}^{+}$as well as visible and $\mathrm{VUV}$ fluorescence have been used for classifications of Rydberg series converging to the $\mathrm{X}, \mathrm{A}, \mathrm{B}$ and $\mathrm{C}$ states in $\mathrm{CO}_{2}^{+}$. A transition to a bent valence state has been recorded and discussed. Neopentane is a well-known example of a high-symmetry molecule where our PIE spectrum shows a broad shape resonance around $16 \mathrm{eV}$ which decays preferentially through the $3 \mathrm{t}_{2}^{-1}$ ionization channel.

\section{References}

1. Berg, L.-E., Erman, P., Källne, E., Sorensen, S.L. and Sundström, G., Physica Scripta 44 (1991) 131-137

2. Erman, P., Karawajczyk, A., Rachlew-Källne, E., Sorensen, S.L., Strömholm, C. amd Kirm, M., J.Phys. B26(1993)4483 - 4490

3. Berg, L.-E., Erman, P., Källne, E., Sorensen, S.L. and Sundström, G., Physica Scripta 44 (1991)328 - 335

4. Erman, P., Karawajczyk, A., Rachlew-Källne, E., Sorensen, S.L. and Strömholm, C., Physica Scripta 49(1994) 308 - 315

5. Erman, P., Rachlew-Källne, E., Sorensen, S.L., Z.Phys.D (in press)

6. Erman, P., Karawajczyk, A., Rachlew-Källne, E. and Strömholm, C., Physica Scripta submitted

7. Berg, L.-E, Karawajczyk, A. and Strömholm, C., J.Phys.B., submitted

8. Sorensen, S.L., Karawajezyk, A., Rachlew-Källne, E., Strömholm C. and Kirm, M., J.Chem.Phys., submitted

9. Cauletti, C., Stranges, S., Karawajczyk, A., Rachlew-Källne, E., Sorensen, S.L., Kirm, M. and Adam, M.Y., Chemical Physics, submitted 